\title{
A Synovial Cyst of the Temporomandibular Joint
}

Florian Chatelet ${ }^{(D)}, \mathrm{MD}$, Ludovic Benichou, MD, Department of Maxillo-facial Surgery and Stomatology, Groupe Hospitalier Paris Saint-Joseph; Serge Ketoff, MD, Department of Maxillo-facial Surgery and Stomatology, Groupe Hospitalier Paris Saint-Joseph, and Medical Practice, Paris, France. Address correspondence to Dr. F. Chatelet, Department of Maxillo-facial Surgery and Stomatology, Groupe Hospitalier Paris Saint-Joseph, 185 Rue Raymond Losserand 75014 Paris, France. Email: chatelet.florian@gmail.com. This study has been approved by the institutional ethics committee (number IRB00012157, initial agreement 419) and registered on the French National Institute of Health Data platform (MR5712250520). We obtained the patient's written informed consent to publish the material.

A 25-year-old woman without personal medical history complained of a unilateral preauricular pain, increased by temporomandibular joint (TMJ) mobilization, that had been evolving for a few months. She had no history of traumatic injury. Clinical examination revealed a tender right preauricular mass, and a reduced mouth opening, with a maximal opening of $33 \mathrm{~mm}$. Oral examination revealed normal occlusion.

Magnetic resonance imaging (MRI) was performed and revealed a well-delimitated and homogeneous cystic lesion, measured at $12 \times 8 \times 10 \mathrm{~mm}$, with a T2-weighted hypersignal (Figure 1A), and a T1-weighted hyposignal, without enhancement after gadolinium injection (Figure 1B), in the right temporomandibular region. A surgical exploration found a cystic mass related to the TMJ (Figure 2). Histopathological examination confirmed the diagnosis of a synovial cyst.

A synovial cyst located in in the TMJ is rare, and to date only 24 cases of synovial cyst of the TMJ have been reported in the literature $^{1}$. The main differential diagnosis is represented by the ganglion cyst and the final diagnostic is usually made on histological examination ${ }^{2}$. Surgical excision is the main treatment, with good results. Recurrence rate seems to be low, without any recurrence reported in the literature, but persistent postoperative pain is possible ${ }^{1}$ Intraarticular injection or aspiration has also been described, without success ${ }^{1,3}$.

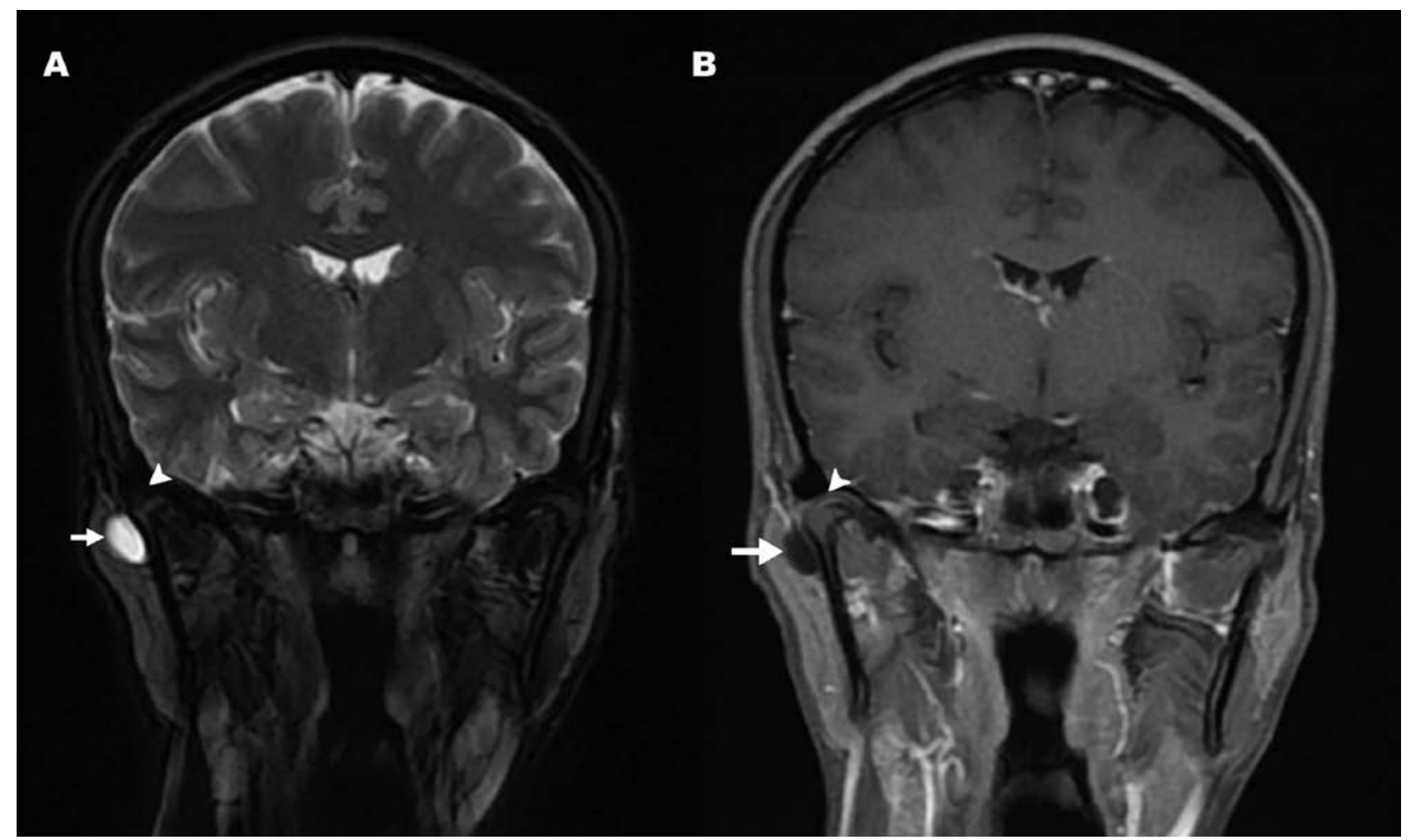

Figure 1. MRI showing a well-delimitated and homogeneous cystic lesion (white arrow), with (A) a T2-weighted hypersignal, and (B) a T1-weighted hyposignal, without enhancement after gadolinium injection, appended to the temporomandibular joint (white arrowhead). MRI: magnetic resonance imaging. 


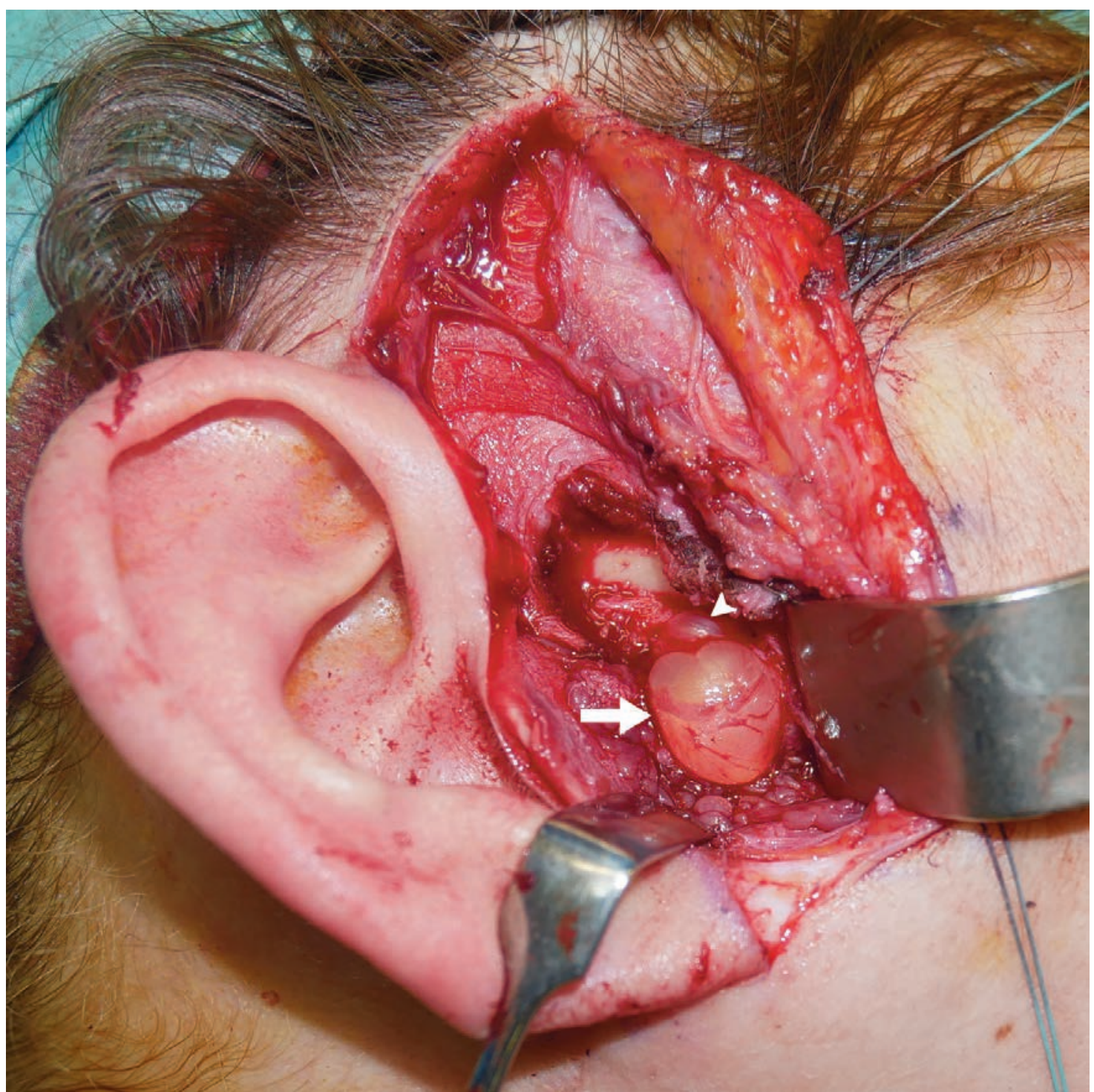

Figure 2. Surgical view after dissection of the synovial cyst (white arrow) related to the TMJ capsule (white arrowhead). TMJ: temporomandibular joint.

\section{REFERENCES}

1. Maribo Y, Stokbro K, Aagaard E, Larsen SR, Thygesen T. Synovial cysts in the temporomandibular joint: a case report and critical review of the literature. J Oral Maxillofac Res 2019;10:e4.

2. Vera-Sirera B, Tomás-Amerigo JA, Baquero C, Vera-Sempere FJ. Synovial cysts of the temporomandibular joint: an immunohistochemical characterization and literature review. Case Rep Pathol 2013;2013:508619.

3. Wu CI, Liu KW, Hsu YC, Chiang IP, Chang SC. Treatment of temporomandibular joint ganglion cyst. J Craniofac Surg 2011;22:1935-7. 